\title{
Mechanism of endogenous digitalis-like factor-induced vascular endothelial cell damage in patients with severe preeclampsia
}

\author{
MEI PENG, MENGYUAN YANG, YILING DING, LING YU, YALI DENG, WEISI LAI and YUN HU
}

Department of Gynaecology and Obstetrics, The Second Xiangya Hospital of

Central South University, Changsha, Hunan 410011, P.R. China

Received October 15, 2016; Accepted November 23, 2017

DOI: $10.3892 / \mathrm{ijmm} .2017 .3316$

\begin{abstract}
Although endogenous digitalis-like factor (EDLF) is associated with the development of various physical disorders, the role in preeclampsia remains unclear. This study investigated the effects of EDLF on vascular endothelial cell damage in patients with preeclampsia and the potential mechanisms. From July 2014 to July 2015, 120 singleton pregnancy cases underwent a prenatal examination, inpatient delivery and had normal blood pressure were included in the study, either as patients with severe preeclampsia or the control patients. Serum EDLF levels were compared in these two groups, and an in vitro hypoxic trophocyte-induced vascular endothelial cell damage model was established to explore the changes in hypoxic trophocyte EDLF level and the subsequent effects on human umbilical vein endothelial cells (HUVECs). Nuclear factor- $\kappa \mathrm{B}(\mathrm{NF}-\kappa \mathrm{B})$ p65 gene expression was silenced in hypoxic trophocytes, and EDLF levels and HUVEC damage were subsequently assessed. Serum EDLF levels were significantly higher in the severe preeclampsia cases than in the controls at the same gestational week $(\mathrm{P}<0.001)$. EDLF levels in hypoxic trophocytes increased with the increasing co-culture duration. Damage to the biofunctions of HUVECs co-cultured with hypoxic trophocytes also increased with co-culture duration. However, silencing of NF- $\mathrm{BB}$ p65 in the hypoxic trophocytes reduced the EDLF levels. Annexin A2 was highly expressed in HUVECs, and no biofunctions were significantly damaged $(\mathrm{P}<0.05)$ compared with the group without receiving NF- $\kappa B$ p65 silencing. Serum EDLF levels were significantly higher in patients with severe preeclampsia compared with the controls. The results of the current study
\end{abstract}

Correspondence to: Professor Yiling Ding, Department of Gynaecology and Obstetrics, The Second Xiangya Hospital of Central South University, 139 People's Middle Road, Furong, Changsha, Hunan 410011, P.R. China

E-mail: dingyl@csu.edu.cn

Key words: preeclampsia, endogenous digitalis-like factor, Annexin A2, human umbilical vein endothelial cells, nuclear factor- $\kappa \mathrm{B}$ p 65 , nitric oxide indicate that NF- $\mathrm{BB}$ p65 has a role in regulating EDLF production in hypoxic trophocytes.

\section{Introduction}

Preeclampsia is a common complication during pregnancy that can occur after 20 weeks of gestation. The clinical manifestations of preeclampsia include hypertension, proteinuria and edema. This complication triggers systemic disorders of multiple organs, including the brain, eyes, liver and kidneys (1), which greatly affect the health of the mother and fetus. Preeclampsia can cause multisystem damage, is closely associated with adverse pregnancy outcomes and has a high morbidity of 5-7\% (2).

According to the complex multifactorial pathogenesis of preeclampsia, symptomatic treatment remains the principle therapeutic strategy, rather than etiological treatment. Currently, the most effective treatment remains pregnancy termination (3). The pathological mechanism involves insufficient vascular remodeling of the placental bed, placental ischemia and anoxia, and secondary systemic endothelial injury and/or activation (4). The patient improves following delivery of the placenta, which may indicate that detrimental factors generated in the placenta have an important role in inducing the associated endothelial cell damage (5). These detrimental factors may directly or indirectly damage vascular epithelial cells and cause organ disorders in the mother.

Endogenous digitalis-like factor (EDLF) is a micromolecular polypeptide, most of which binds non-covalently with plasma protein. It has digitalis-like activity, and inhibits the specific binding of ATPase to its receptor, and also suppresses the cell membrane sodium pump in cardiac tissue, the vascular wall, the central nervous system, the renal tubular epithelium and others. Thus, EDLF regulates water and salt metabolism, and vascular wall tension, and thus has cardiac, natriuretic and vasoconstrictive roles (6). EDLF is associated with the development of various heart, vascular, kidney and liver diseases (7). Organ damage in preeclampsia predominantly involves the cardiovascular system, liver and kidneys, indicating the potential role of EDLF in the development of preeclampsia. EDLF biosynthesis is closely associated with cholesterol side-chain cleavage in the metabolism of progesterone and pregnenolone (8). Progesterone is a hormone produced by the 
placenta during gestation. Another study reported that nuclear factor- $\kappa \mathrm{B}(\mathrm{NF}-\kappa \mathrm{B})$ is activated in the placenta in preeclampsia; $\mathrm{NF}-\kappa \mathrm{B}$ participates in local inflammatory reactions in the placenta and the development of preeclampsia (9).

Activated $\mathrm{NF}-\kappa \mathrm{B}$ participates in initiating and regulating the transcription of multiple genes associated with immunity, inflammation, apoptosis and cell proliferation $(10,11)$. Cellular proliferation and differentiation are involved in embryo implantation and development (12). Multiple inflammatory factors are involved in various physical and pathological processes, including premature delivery and the initiation of parturition (13). NF- $\kappa \mathrm{B}$ p65, the most explored subunit of $\mathrm{NF}-\kappa \mathrm{B}$, has a more crucial role than the other subunits. NF- $\kappa \mathrm{B}$ p65 is involved in physical processes including embryo implantation, pregnancy maintenance and the initiation of parturition (14), and the development and progression of preeclampsia (15-18). Nitric oxide (NO) is an effective vasodilator that regulates angiostasis and tissue blood flow; in addition, NO can regulate arterial blood pressure, maternal organ perfusion, the fetal-placental vascular response and placental blood flow (19). The widely accepted pathogenesis of preeclampsia includes epithelial cell damage, a subsequent decrease in NO production and several further pathological changes. In the blood vessel endothelium, NO synthase (NOS) is the rate-limiting enzyme in NO synthesis, and NOS expression is dependent on $\mathrm{NF}-\kappa \mathrm{B}$ regulation (20). These data suggest that $N F-\kappa B$ facilitates the important role of NO in preeclampsia by regulating NOS.

Although EDLF is closely associated with vascular epithelial damage and is a natural inhibitor of sodium-potassium ATPase, it affects the blood vessel endothelium through other pathways. Various effects of EDLF on blood vessel endothelial cells were revealed by differences in protein expression, and certain potential key target proteins were discovered. Annexin A2 is an important target of EDLS (via alteration of the expression of Annexin A2 to exert influence on the functions of Annexin A2); Annexin A2 is closely associated with the blood vessel endothelium (21). A study on the association between the Annexin A family and preeclampsia demonstrated that decreased Annexin A2 production may be associated with the development of preeclampsia (22).

Based on the aforementioned data, we hypothesize that EDLF may be a detrimental factor originating from the placenta that contributes to the development of preeclampsia. Furthermore, by regulating EDLF expression in hypoxic trophocytes, NF- $\mathrm{B}$ p 65 may affect the production of Annexin A2 (an EDLF target protein), thus decreasing NO production and resulting in the development of preeclampsia. This is a potential mechanism underlying vascular endothelial cell damage in preeclampsia. To evaluate this hypothesis, hypoxic trophocytes and human umbilical vein endothelial cells (HUVECs) were co-cultured, and changes in EDLF production by hypoxic trophocytes and the influence of EDLF on HUVEC functions were determined. Subsequently, the potential mechanism underlying the effect of EDLF generated by hypoxic trophocytes on the biofunctions of HUVECs was explored.

\section{Materials and methods}

Patients. Among the singleton pregnancy outpatient cases in the Second Xiangya Hospital of Central South University
(Changsha, China) from July 2014 to July 2015, 60 cases of severe preeclampsia (age, $33.73 \pm 5.49$ years) were randomly selected and included in the severe preeclampsia group. The diagnostic criteria were based on those reported in the literature (23): i) Systolic pressure $\geq 160 \mathrm{mmHg}$ and/or diastolic pressure $\geq 110 \mathrm{mmHg}$; ii) proteinuria $\geq 5,000 \mathrm{mg} / 24 \mathrm{~h}$ or random urine protein $(+++)$; iii) persistent headache, vision disorder or other cranial nerve symptoms; iv) persistent epigastric pain, subcapsular hematoma of the liver or hepatorrhexis symptoms; v) hepatosis (increased serum ALT or AST); vi) abnormal renal function (oliguria: $24 \mathrm{~h}$ urine volume $<400 \mathrm{ml}$ or urine volume per hour $<17 \mathrm{ml}$; or serum creatinine $>106 \mathrm{ng} / \mathrm{l}$ ); vii) hypoproteinemia, hydrothorax or seroperitoneum; viii) blood system disorders: microangiopathy hemolysis or blood platelet count <100x109/1; ix) cardiac failure and pulmonary edema; $x$ ) fetal growth restriction or oligohydramnios; or xi) early-onset preeclampsia before 34 weeks of pregnancy. The exclusion criteria included the following: i) Chronic hypertension; severe diseases of the heart, lungs, kidneys, liver, or thyroid, or other endocrine diseases experienced before pregnancy; ii) obstetric complications, including placental abruption, gestational diabetes mellitus, premature rupture of membranes, maternal-fetal blood group incompatibility, or placenta previa; iii) the use of assisted reproductive technology; and iv) administration of abortion prevention medicine.

The 60 singleton pregnancy cases with a prenatal examination or inpatient delivery and normal blood pressure during the same period were included in the control group (age, $32.73 \pm 4.36$ years). Patient information, such as age, blood pressure, height, weight, gestational weeks, and parity and gravidity, was collected and recorded. Peripheral venous blood samples were centrifuged to collect sera. EDLF concentrations were determined using EDLF radioimmunoassay kit (cat. no. FM0063; Beijing North Institute of Biological Technology, Beijing, China; used in the in vitro experiments as well). As numerous factors can influence the outcome of this radioimmunoassay (such as cross reactivity with digoxin and ouabain and experimental conditions) (24-26), samples were collected strictly according to the inclusion criteria, the blood collection time and conditions were highly standardized, and the experimental procedures (such as incubation and centrifugation conditions) were performed in strict accordance with the instructions provided with the kit.

This study was approved by the Ethics Committee of the Second Xiangya Hospital of Central South University. Informed consent was obtained from all participants.

Experimental cells. Human BeWo placental choriocarcinoma trophocyte cells (Shanghai Sixin Biotechnology, Ltd., Shanghai, China) were used in this study (27). HUVECs were purchased from the Physical Laboratory of Xiangya School of Medicine, South Central University.

Trophocyte and HUVEC cultures. HUVECs were cultured in Dulbecco's modified Eagle's medium (Hyclone, Logan, UT, USA), and BeWo cells were cultured in F12K medium (Life Technologies; Thermo Fisher Scientific, Inc., Waltham, MA, USA); both cultures were supplemented with fetal bovine serum (FBS; Gibco, Invitrogen, Grand Island, NY, USA) and 
incubated in saturated humidity and $5 \% \mathrm{CO}_{2}$ at $37^{\circ} \mathrm{C}$. Culture media were changed every 2 days. Cells were passaged with $0.25 \%$ trypsin upon reaching $80 \%$ confluence.

HUVEC confluence. HUVECs in the logarithmic growth phase were diluted to a concentration of $1 \times 10^{5} / 1$, seeded into 5 wells of a 12-well plate at $1 \mathrm{ml} /$ well and incubated in saturated humidity and $5 \% \mathrm{CO}_{2}$ at $37^{\circ} \mathrm{C}$. Cell growth and confluence were observed regularly and frequently by light microscopy (BX53; Olympus Corporation, Tokyo, Japan). The basic features of healthy cells included the following: Proper transparency, low intracytoplasmic granular substance level, small cytoplasmic volume and no hypertrophy. In addition, the healthy cells adhered well and grew evenly, with no or few cells floating in the culture medium. Healthy cells were co-cultured with hypoxic trophocytes.

Treatment of BeWo trophocytes with hypoxia. Following trypsinization $(0.25 \%$ ), centrifugation (at $350 \mathrm{x} \mathrm{g}$ at room temperature for $5 \mathrm{~min}$ ) and resuspension (in complete medium containing $10 \% \mathrm{FBS}$ ), BeWo cells in the logarithmic growth phase were diluted to a concentration of $4 \times 10^{5} / 1$, seeded into 5 wells of a 12-well plate at $1 \mathrm{ml}$ per well and cultured overnight for adherence in saturated humidity and $5 \% \mathrm{CO}_{2}$ at $37^{\circ} \mathrm{C}$. A sterile stock solution of $\mathrm{CoCl}_{2}(1 \mathrm{~mol} / \mathrm{l})$ was prepared and diluted in complete culture medium to a concentration of $10 \mathrm{mmol} / 1$ to form the working solution. The medium was replaced with $1 \mathrm{ml}$ of fresh medium. Then, $30 \mu \mathrm{l}$ of the working $\mathrm{CoCl}_{2}$ solution was added for a final concentration of $300 \mu \mathrm{mol} / 1$. For the hypoxia treatment, these cells were incubated in saturated humidity and $5 \% \mathrm{CO}_{2}$ at $37^{\circ} \mathrm{C}$ for $24 \mathrm{~h}$.

Transfection of hypoxic trophocytes with the NF- $\kappa B$ plasmid. Hypoxia-treated BeWo cells were divided into 3 groups, and culture media were replaced with antibiotic-free F12K medium ( $2 \mathrm{ml} /$ bottle). The NF- $\mathrm{KBsi}-2$ plasmid (Shanghai GeneChem Co., Ltd., Shanghai, China) was transfected into these cells as follows. NF- $\kappa$ Bsi-2 $(20 \mu \mathrm{l})$ was added to a sterile Eppendorf tube, and Lipofectamine ${ }^{\circledR} 2000$ transfection reagent $(5 \mu \mathrm{l}$; GenStar, Beijing, China) was added to another sterile Eppendorf tube. The sequences of si-1, si-2 and si-3 were CCGGA CUUGUUUACAAAGU, CUACUGUAGGUCUAAGCUA, and UCUACUGUAGGUCUAAGCU, respectively. Serum-free F12 medium $(200 \mu \mathrm{l})$ was added to these tubes, which were then allowed to stand for $5 \mathrm{~min}$ at $26^{\circ} \mathrm{C}$. Following gentle mixing, the tubes were allowed to stand for another $20 \mathrm{~min}$. The mixtures were then added to culture medium, and the final concentrations were adjusted to $100 \mathrm{pmol} / \mathrm{ml}$. Untransfected cells were used as the mock control. Scramble control was used (ACGUGACACGUUCGGUATT). siRNA naked fragment (FTIC-conjugated) conferred fluorescence to the cells.

Co-culture of transfected trophocytes and HUVECs. HUVECs were placed in the upper chamber of a co-culture chamber (co-culture for $48 \mathrm{~h}$ ), and NF- $\kappa \mathrm{Bsi}$-2-transfected trophocytes were placed in the lower chamber; these cells were co-cultured for $24 \mathrm{~h}$. Then, the culture medium in both chambers was refreshed, and fluorescein isothiocyanate (FITC)-labeled glucan (10 ng/ml; Sigma-Aldrich; Merck KGaA, Darmstadt, Germany) was added to the upper chamber. The cultures were incubated for an additional 12, 24, 48, 72, 96 or $120 \mathrm{~h}$. Co-cultures of HUVECs and mock control trophocytes were prepared, cultured and analyzed in parallel.

Evaluation of HUVEC barrier function. The culture supernatant in the lower chamber was harvested $(500 \mu \mathrm{l})$ at the designated time-points, and a fluorospectrophotometer (excitation wavelength, $488 \mathrm{~nm}$; sensitivity, 50) was used to determine the fluorescence intensity of FITC. All the operations were performed in the dark.

MTT assay to evaluate HUVEC proliferation. HUVEC proliferation was evaluated using MTT assays, which were performed in accordance with the manufacturer's instructions (Sigma-Aldrich; Merck KGaA). The endothelial cells in the upper chamber were treated with trypsin $(0.25 \%)$, resuspended, seeded into a 96-well plate at a concentration of $1 \times 10^{4}$ cells/well and incubated for $48 \mathrm{~h}$. Then, $20 \mu \mathrm{l}$ MTT solution $(5 \mathrm{mg} / \mathrm{ml})$ was added to each well, and the medium was discarded after $4 \mathrm{~h}$ of incubation. Subsequently, dimethyl sulfoxide $(150 \mu \mathrm{l})$ was added, and after $10 \mathrm{~min}$ of incubation at room temperature, $100 \mu \mathrm{l}$ from each well was transferred into the coated wells of a 96-well plate. Absorbance values were determined at a wavelength of $490 \mathrm{~nm}$ measured using a 960PRO fluorospectrophotometer (INESA; Shanghai, China; http://en.inesa-instrument.com/index.html). The other groups were analyzed via the procedures described above.

Nitrate reductase activity assay to determine the NO concentration. The NO level in the HUVEC culture supernatant was detected using nitrate reductase activity assays (NO detection kit; cat. no. A012; Nanjing Jiancheng Bioengineering Institute, Nanjing, China). Endothelial cell culture supernatants from the upper chambers were harvested at the designated time-points (500 $\mu \mathrm{l} /$ group), and the reagents were mixed well with the specimens according to the manufacturer's instructions (Nanjing Jiancheng Bioengineering Institute) and incubated at room temperature for $10 \mathrm{~min}$. Then, the absorbance values were determined (550 $\mathrm{nm}$ wavelength and $0.5 \mathrm{~cm}$ optical path) and normalized to that of double-distilled water as the blank.

Western blot analysis of Annexin A2 expression in HUVECs. Cells were suspended $(20 \mu \mathrm{l})$ and treated with radioimmunoprecipitation lysis buffer (100 $\mu \mathrm{l}$; Beyotime, Shanghai, China) containing $1 \mu \mathrm{l}$ each of phenylmethylsulfonyl fluoride and protease and protein tyrosine phosphatase inhibitors. Then, the cells were incubated on ice for $30 \mathrm{~min}$ and centrifuged at $350 \mathrm{x} \mathrm{g}$ at $4^{\circ} \mathrm{C}$ for $5 \mathrm{~min}$. The supernatant was harvested and stored at $-20^{\circ} \mathrm{C}$; the Laemmli system was used. The concentrations of the spacer and separation gels were 5 and $12 \%$, respectively. The prepared separation gel was gently infused into the space between the fixed double-paned glass, and isopropanol was used to seal the top; the gels were allowed to set for $30 \mathrm{~min}$ at room temperature. Protein levels were determined using a bicinchoninic acid protein determination kit (Wellbio, Changsha, China). A total of $25 \mu \mathrm{g}$ protein was loaded per lane, with $15 \%$ gel. NC membranes were used for protein transfer. TBST containing 5\% skim milk was used for blocking. After immersing, the membranes were placed 
Table I. Comparison of serum EDLS levels between the two groups.

\begin{tabular}{lcc}
\hline Group & Serum EDLS (ng/l) & P-value $^{\mathrm{a}}$ \\
\hline Control & $66.49 \pm 10.36$ & $\mathrm{P}<0.01$ \\
Severe preeclampsia & $125.09 \pm 14.33$ & \\
\hline
\end{tabular}

${ }^{a}$ Healthy control vs. severe preeclampsia. EDLS, endogenous digitalis-like factor.

at room temperature for $1 \mathrm{~h}$. The following procedures included primary antibody incubation, secondary antibody incubation, development (or staining) and exposure (28). The primary antibodies were as follows: NF- $\mathrm{kB}$ (cat. no. 6956S; source, mouse; dilution, 1,000; molecular weight, $65 \mathrm{kDa}$; Cell Signaling Technology, Beverly, MA, USA), Annexin A2 (cat. no. 11256-1-AP; source, rabbit; dilution, 1,000; molecular weight, $36 \mathrm{kDa}$; Proteintech, Rosemont, IL, USA), Actin (cat. no. 60008-1-Ig; source, mouse; dilution, 4,000; molecular weight, $42 \mathrm{kDa}$; Proteintech). The membranes were incubated with the primarily antibodies at $4^{\circ} \mathrm{C}$ overnight. After incubation, they were washed thrice with TBS-T, for $15 \mathrm{~min}$ per wash. HRP-conjugated goat anti-rabbit IgG was used as the secondary antibody (dilution, 1: 3,000; Proteintech) (incubation for 45-60 min). The samples were washed thrice, for $15 \mathrm{~min}$ per wash. The exposure was performed using superECL Plus (Thermo Pierce, Rockford, IL, USA). Western blot analysis was performed using Quantity One software (4.6.2; Bio-Rad Laboratories, Inc., Hercules, CA, USA).

Reverse transcription-quantitative polymerase chain reaction $(R T-q P C R)$. In addition, Annexin a2mRNA was detected using a reverse transcription kit [Fermentas (Thermo Fisher Scientific, Inc., Pittsburgh, PA, USA)]. Annexin A2 mRNA levels in HUVECs were determined by RT-qPCR. Total RNA was extracted with TRIzol reagent (Life Technologies; Thermo Fisher Scientific, Inc.) according to the manufacturer's instructions. The purity and concentration of total RNA were determined by ultraviolet spectrophotometry. Actin was used as a normalization control. Reverse transcription was performed with a kit from Fermentas. Primers were designed with Primer 5.0 software (PREMIER Biosoft, Vancouver, Canada) and synthesized by Invitrogen (Thermo Fisher Scientific, Inc.). The extension length of the Annexin A2 primers (forward, 5'-GCCCTGGCAAAGGGTAGA-3' and reverse, 5'-ACGCTCCGCTCGGTCAT-3') generated a product of $149 \mathrm{bp}$. The actin primers (forward, 5'-CATCCTGCGTCT GGACCTGG-3' and reverse 5'-TAATGTCACGCACGA TTTCC-3') generated a product of $107 \mathrm{bp}$. One sample was analyzed in three parallel experimental wells. The total reaction system of $30 \mu \mathrm{l}$ contained RT product as a template $(1 \mu \mathrm{l})$, forward primer $(10 \mu \mathrm{M}, 0.5 \mu \mathrm{l})$, reverse primer $(10 \mu \mathrm{M}, 0.5 \mu \mathrm{l})$, PCR-grade $\mathrm{H}_{2} \mathrm{O}(13 \mu \mathrm{l})$ and $2 \mathrm{X}$ SYBR-Green PCR Master Mix (15 $\mu$ l; Applied Biosystems, Foster City, CA, USA). The qPCR amplification conditions were as follows: $95^{\circ} \mathrm{C}$ for $10 \mathrm{~min}$, followed by 40 cycles of $95^{\circ} \mathrm{C}$ for $10 \mathrm{sec}$ and $60^{\circ} \mathrm{C}$ for $50 \mathrm{sec}$. The melting curves were collected at $60-95^{\circ} \mathrm{C}$. The qPCR $(5 \mu \mathrm{l})$ products were analyzed via $2 \%$ agarose gel elec- trophoresis. Annexin A2 mRNA was detected with a Gel Doc XR gel-imaging system (Bio-Rad Laboratories, Inc.). Data were analyzed using the qPCR analytical tool, and quantification was performed using the $2^{-\Delta \Delta \mathrm{Ct}}$ method.

Statistical analysis. The data were analyzed using SPSS 19.0, and data are presented as the mean \pm standard deviation. Normality tests were performed with the Kolmogorov-Smirnov and Shapiro-Wilk tests. The homogeneity of the variance between groups was assessed via Levene's method. The intergroup differences of paired data were analyzed using the t-test. Pairwise comparisons of differences among multiple groups were performed using the Student-Newman-Keuls-q test. $\mathrm{P}<0.05$ was considered to indicate a statistically significant difference.

\section{Results}

EDLF levels. Serum EDLF levels in the severe preeclampsia patients and the normal pregnancy controls are presented in Table I. No significant differences were identified in gestational weeks, age, weight, height, or parity and gravidity between the two groups $(P>0.05)$. Serum EDLF levels were significantly higher in severe preeclampsia cases compared with normal pregnancy cases $(\mathrm{P}<0.05)$.

HUVEC morphology. HUVEC morphology was observed by light microscopy (Fig. 1). The cells grew well to confluency and exhibited a cobblestone-like arrangement, sharp edges, abundant cytoplasm, elliptical shape, centralized nuclei and clear nucleoli.

Morphological changes in trophocytes following transfection. BeWo cells exhibiting the typical characteristics were passaged after 3 days of culture and observed by light microscopy after an additional 2 days (Fig. 2). The cells showed healthy and compact growth, and had formed multiple layers.

Silencing efficiency of $N F-\kappa B$ siRNA. The gene silencing efficiency of NF- $\kappa \mathrm{B}$ siRNA was evaluated by western blot analysis (Fig. 3 and Table II). NF- $\kappa B s i-2$ exerted the best gene-silencing effect and was therefore used in the subsequent experiments.

Morphology of trophocytes following transfection. Fluorescently-labeled siRNA-transfected trophocytes were observed by fluorescence microscopy. Green fluorescence was successfully expressed in the trophocytes (Fig. 4).

EDLF levels in hypoxic trophocytes at different time points following $N F-\kappa B$ p 65 gene silencing. The culture supernatant of hypoxic trophocytes was harvested at different time points, and EDLF concentration was determined by radioimmunoassay. EDLF expression levels were increased over time in untransfected hypoxic trophocytes co-cultured with HUVECs. However, in the cells transfected with NF- $\kappa$ Bsi-2 the cells exhibited no significant changes in EDLF expression over time under the same conditions (Table III).

Effect of NF- $\kappa B$ p65 silencing in hypoxic trophocytes on HUVEC functions 
A
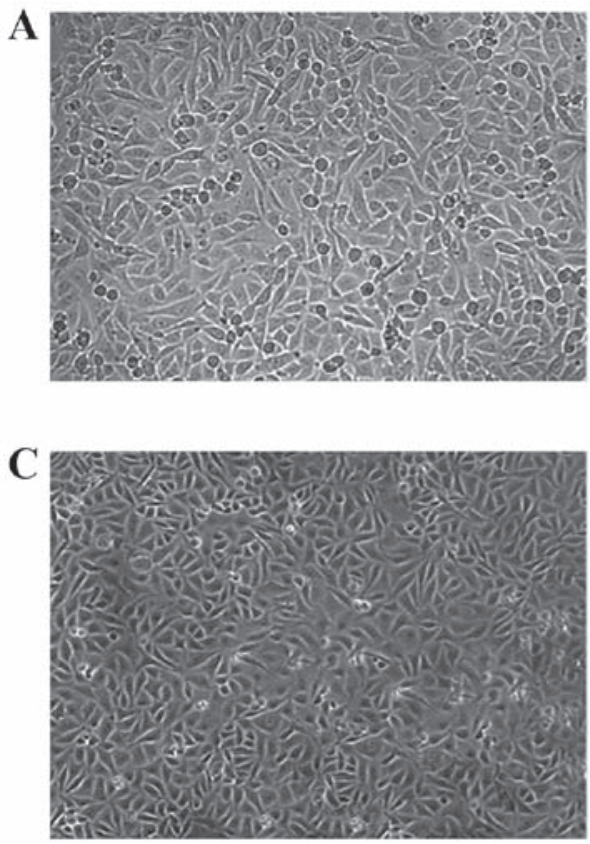

B

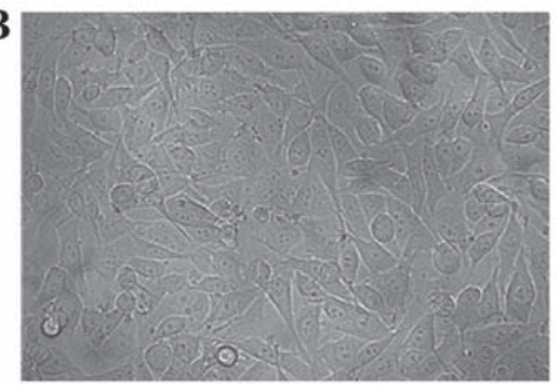

D

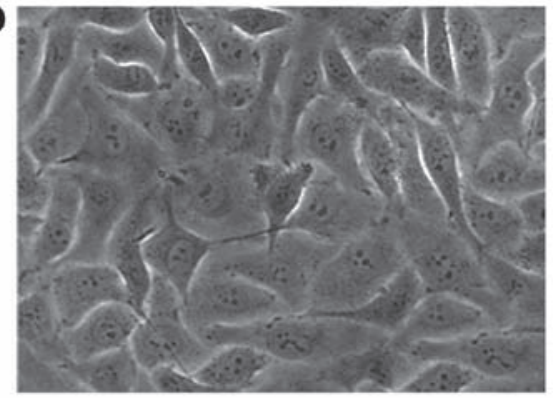

Figure 1. HUVEC morphology under light microscopy. (A) Confluent HUVECs fused into a monolayer (x100). (B) Confluent HUVECs (x200). (C) HUVECs growing well (x100). (D) HUVECs growing well (x400). HUVEC, human umbilical vein endothelial cell.

A

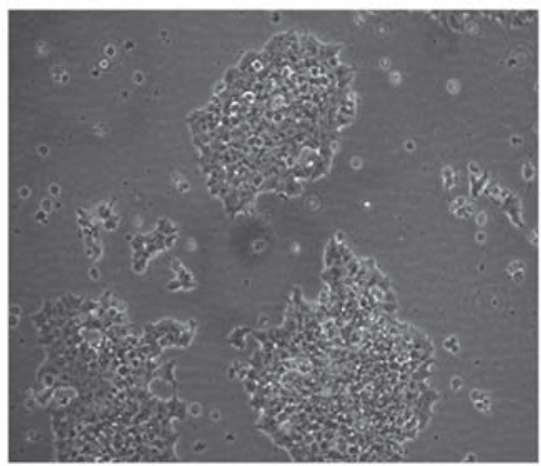

B

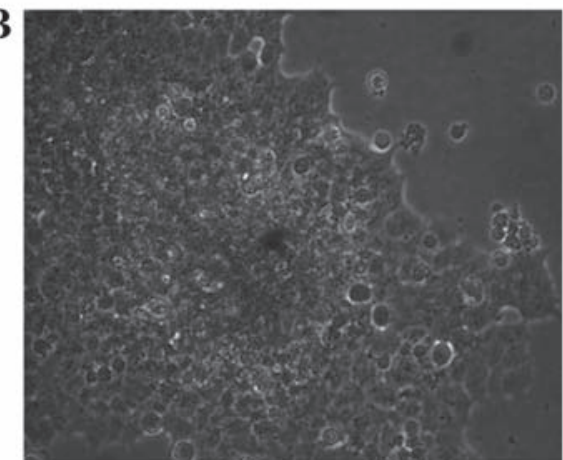

Figure 2. BeWo morphology as viewed by light microscopy. (A) x100. (B) x200.

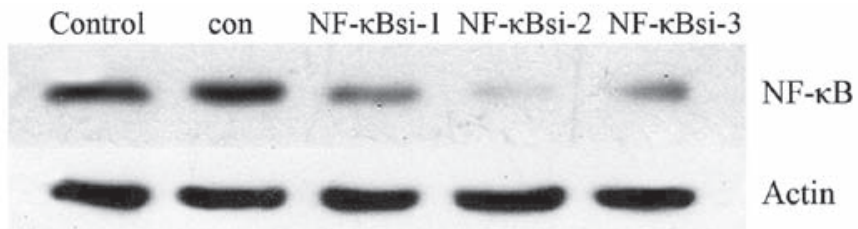

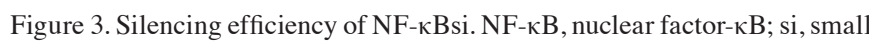
interfering RNA.
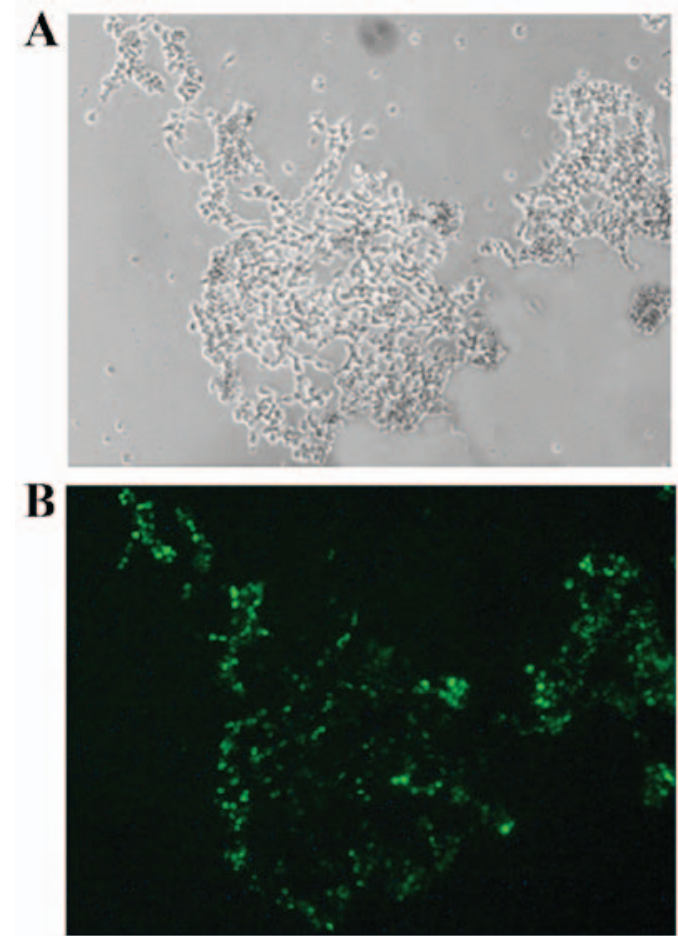

Figure 4. BeWo cells following transfection (x100). (A) Prior to and (B) following transfection with nuclear factor- $\kappa \mathrm{B}$ small interfering RNA plasmid. Control, normally cultured cells (cells and corresponding medium only); Con, cultured cells transfected with anti-sense strand vectors.

Proliferative activity. The proliferation of HUVECs co-cultured with hypoxic trophocytes changed according to the co-culture time (Table IV). Based on the MTT assay results, HUVEC proliferation gradually decreased with increasing time of co-culture with untransfected trophocytes. After transfection, the proliferation of HUVECs co-cultured 
Table II. Gene silencing by NF-кBsi as determined by western blot analysis.

\begin{tabular}{|c|c|c|c|c|c|}
\hline & Mock & Control & NF- $\kappa$ Bsi-1 & $\mathrm{NF}-\kappa \mathrm{Bsi}-2$ & NF- $\kappa$ Bsi-3 \\
\hline $\mathrm{NF}-\kappa \mathrm{B}$ & 67.68 & 71.52 & 43.91 & 20.9 & 35.5 \\
\hline Actin & 104.97 & 102.43 & 102.54 & 112.02 & 98.94 \\
\hline N/actin & 0.645 & 0.698 & 0.428 & 0.187 & 0.359 \\
\hline
\end{tabular}

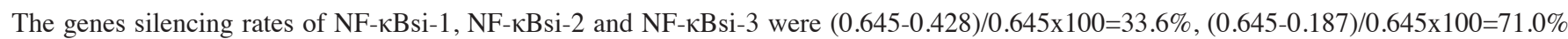
and $(0.645-0.359) / 0.645 \times 100=44.3 \%$. NF- $\kappa$ Bsi-2 was selected in future experiments. NF- $\kappa \mathrm{B}$, nuclear factor- $\kappa \mathrm{B}$; si, small interfering RNA.

Table III. Comparison of EDLS concentration expression in hypoxic trophocytes.

\begin{tabular}{|c|c|c|}
\hline \multirow{2}{*}{$\begin{array}{l}\text { Co-culture } \\
\text { time }\end{array}$} & \multicolumn{2}{|c|}{ EDLS (ng/l) } \\
\hline & Untransfected & NF- $\kappa$ Bsi-2 \\
\hline $12 \mathrm{~h}$ & $1.4657 \pm 0.069$ & $1.4829 \pm 0.05730$ \\
\hline $24 \mathrm{~h}$ & $1.8817 \pm 0.0084$ & $1.5234 \pm 0.05945^{\mathrm{a}}$ \\
\hline $48 \mathrm{~h}$ & $2.5149 \pm 0.0503$ & $1.6196 \pm 0.06512^{b}$ \\
\hline $72 \mathrm{~h}$ & $2.8244 \pm 0.0445$ & $1.6501 \pm 0.04676^{b}$ \\
\hline $96 \mathrm{~h}$ & $3.0932 \pm 0.0925$ & $1.7215 \pm 0.09365^{b}$ \\
\hline $120 \mathrm{~h}$ & $3.1506 \pm 0.1297$ & $1.8380 \pm 0.10294^{b}$ \\
\hline
\end{tabular}

${ }^{\mathrm{a}} \mathrm{P}<0.05$ vs. untransfected; ${ }^{\mathrm{b}} \mathrm{P}<0.01$ vs. untransfected. $\mathrm{n}=3$. Values are presented as the mean \pm standard deviation. EDLS, endogenous digitalis-like factor. NF- $\kappa \mathrm{B}$, nuclear factor- $\kappa \mathrm{B}$; si, small interfering RNA.

with transfected trophocytes gradually increased, exhibiting significant differences after $24 \mathrm{~h}(\mathrm{P}<0.05)$ and $48 \mathrm{~h}(\mathrm{P}<0.01)$.

Barrier function. The barrier function of HUVECs co-cultured with hypoxic trophocytes changed over time (Table V). FITC-conjugated glucan was applied to the co-culture with untransfected hypoxic trophocytes and gradually moved through the HUVEC monolayer from the upper chamber into the lower chamber, which increased the concentration of FITC-glucan in the lower chamber over time, and provided an indicator of the HUVEC barrier function. However, in the culture using NF- $\kappa \mathrm{Bsi}-2$ trophocytes, the amount of FITC-glucan passing through the HUVEC monolayer decreased gradually, and the barrier function damage was relatively improved by $24 \mathrm{~h}$ of culture $(\mathrm{P}<0.05)$ compared with the untransfected cells at $24 \mathrm{~h}$; significant differences were also observed after $48 \mathrm{~h}$ of co-culture $(\mathrm{P}<0.01)$.

NO level. Changes were observed in NO production by HUVECs co-cultured with hypoxic trophocytes (Table VI). In HUVECs cultured with untransfected trophocytes, the relative NO level gradually decreased with increasing co-culture time. However, in HUVECs cultured with NF- $\kappa$ Bsi-2 trophocytes, the relative NO production increased gradually, and was increased compared with the untransfected group by $24 \mathrm{~h}(\mathrm{P}<0.05)$, and significant differences were also observed after $48 \mathrm{~h}(\mathrm{P}<0.01)$.

Annexin A2 expression in co-cultured HUVECs. Annexin A2 expression in HUVECs was determined by western blot anal-
Table IV. Changes in proliferative activity hypoxic trophocytes.

\begin{tabular}{lcc}
\hline & \multicolumn{2}{c}{ Optical density } \\
\cline { 2 - 3 } $\begin{array}{l}\text { Co-culture } \\
\text { time }\end{array}$ & Untransfected & NF- $\kappa$ Bsi-2 \\
\hline $12 \mathrm{~h}$ & $0.7748 \pm 0.01431$ & $0.7888 \pm 0.00258$ \\
$24 \mathrm{~h}$ & $0.7288 \pm 0.02148$ & $0.8025 \pm 0.01108^{\mathrm{a}}$ \\
$48 \mathrm{~h}$ & $0.6688 \pm 0.01872$ & $0.8397 \pm 0.02298^{\mathrm{b}}$ \\
$72 \mathrm{~h}$ & $0.6168 \pm 0.02492$ & $0.8514 \pm 0.02231^{\mathrm{b}}$ \\
$96 \mathrm{~h}$ & $0.5243 \pm 0.36065$ & $0.8636 \pm 0.02731^{\mathrm{b}}$ \\
$120 \mathrm{~h}$ & $0.4517 \pm 0.01589$ & $0.9035 \pm 0.00714^{\mathrm{b}}$ \\
\hline
\end{tabular}

${ }^{\mathrm{a}} \mathrm{P}<0.05$ vs. untransfected; ${ }^{\mathrm{b}} \mathrm{P}<0.01$ vs. untransfected. $\mathrm{n}=3$. NF- $\kappa \mathrm{B}$, nuclear factor- $\kappa \mathrm{B} ;$ si, small interfering RNA.

ysis (Fig. 5; Table VII). In the untransfected group, Annexin A2 protein expression in co-cultured HUVECs decreased over time. Following NF- $\mathrm{KBsi}-2$ transfection of the trophocytes, Annexin A2 levels in HUVECs were increased, beginning at $24 \mathrm{~h}$, and the differences between the untransfected and $\mathrm{NF}-\kappa \mathrm{Bsi}-2$ groups became significant at $72 \mathrm{~h}(\mathrm{P}<0.01)$.

Relative Annexin A2 mRNA expression levels in HUVECs. HUVECs were harvested prior to trophocyte transfection and following transfection with $\mathrm{NF}-\kappa \mathrm{Bsi}-2$, and total RNA was extracted and transcribed into cDNA. Relative Annexin A2 mRNA levels were detected via qPCR, and actin was used for data normalization (Table VIII). Annexin A2 mRNA expression in HUVECs decreased gradually over time when co-cultured with untransfected trophocytes. After $24 \mathrm{~h}$ of co-culture with NF- $\kappa \mathrm{Bsi}$-2-transfected trophocytes, Annexin A2 mRNA levels in HUVECs increased over time compared with the untransfected group $(\mathrm{P}<0.05)$.

\section{Discussion}

Preeclampsia is one of the major causes of mortality in pregnant women and perinatal infants. The fundamental pathological changes include systemic damage to vascular endothelial cells, inflammation-associated systemic small vessel spasms and a hypercoagulable state. These changes can cause various clinical manifestations, including hypertension, edema and proteinuria, and subsequent severe ischemia in vital organs, 
Table V. Changes in human umbilical vein endothelial cell barrier function post-transfection.

\begin{tabular}{|c|c|c|}
\hline \multirow{2}{*}{$\begin{array}{l}\text { Co-culture } \\
\text { time }\end{array}$} & \multicolumn{2}{|c|}{ Fluorescence } \\
\hline & Untransfected & $\mathrm{NF}-\kappa \mathrm{Bsi}-2$ \\
\hline $12 \mathrm{~h}$ & $12.6410 \pm 0.06003$ & $12.0867 \pm 0.06027$ \\
\hline $24 \mathrm{~h}$ & $13.7967 \pm 0.56400$ & $11.5367 \pm 0.43004$ \\
\hline $48 \mathrm{~h}$ & $15.5517 \pm 0.16918$ & $8.6600 \pm 0.39737$ \\
\hline $72 \mathrm{~h}$ & $16.3620 \pm 0.47820$ & $7.5000 \pm 0.63379$ \\
\hline $96 \mathrm{~h}$ & $17.6407 \pm 0.51832$ & $5.8500 \pm 0.6486^{\mathrm{b}}$ \\
\hline $120 \mathrm{~h}$ & $18.6810 \pm 0.63612$ & $4.6867 \pm 0.55519$ \\
\hline
\end{tabular}

${ }^{\mathrm{a}} \mathrm{P}<0.05$ vs. untransfected; ${ }^{\mathrm{b}} \mathrm{P}<0.001$ vs. untransfected. $\mathrm{n}=3 . \mathrm{NF}-\kappa \mathrm{B}$, nuclear factor- $\kappa \mathrm{B}$; si, small interfering RNA.

Table VII. Relative Annexin A2 protein expression levels in human umbilical vein endothelial cells.

Annexin A2 expression

\begin{tabular}{ccc}
$\begin{array}{l}\text { Co-culture } \\
\text { time }\end{array}$ & Untransfected & NF-кBsi-2 \\
\hline $12 \mathrm{~h}$ & $0.5107 \pm 0.00856$ & $0.5210 \pm 0.00897$ \\
$24 \mathrm{~h}$ & $0.4727 \pm 0.00715$ & $0.5633 \pm 0.00770^{\mathrm{a}}$ \\
$48 \mathrm{~h}$ & $0.4180 \pm 0.00608$ & $0.5855 \pm 0.00806^{\mathrm{a}}$ \\
$72 \mathrm{~h}$ & $0.3892 \pm 0.01639$ & $0.5977 \pm 0.00190^{\mathrm{b}}$ \\
$96 \mathrm{~h}$ & $0.3570 \pm 0.01949$ & $0.6003 \pm 0.01961^{\mathrm{b}}$ \\
$120 \mathrm{~h}$ & $0.31176 \pm 0.01071$ & $0.6257 \pm 0.00577^{\mathrm{b}}$ \\
\hline
\end{tabular}

${ }^{\mathrm{a}} \mathrm{P}<0.05$ vs. untransfected; ${ }^{\mathrm{b}} \mathrm{P}<0.01$ vs. untransfected. Annexin $\mathrm{A} 2$ was normalized to the actin gray level. NF- $\kappa \mathrm{B}$, nuclear factor- $\kappa \mathrm{B}$; si, small interfering RNA.

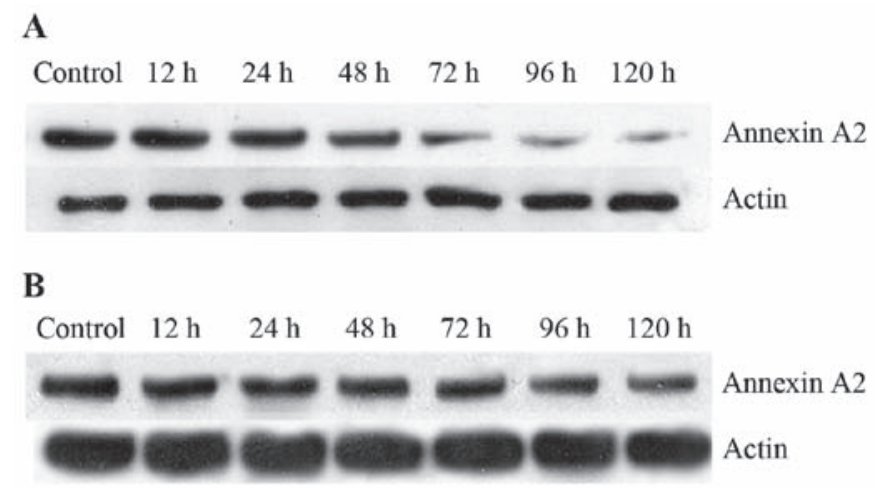

Figure 5. Annexin A2 production in human umbilical vein endothelial cells.

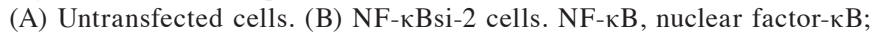
si, small interfering RNA.

including the heart, brain, liver and kidneys. Furthermore, in severe cases, this condition can result in sequelae or mortality in the mother or infant. Although numerous research efforts have been directed toward investigating this condition, its
Table VI. Relative nitric oxide levels in human umbilical vein endothelial cells.

\begin{tabular}{ccc}
\hline & \multicolumn{2}{c}{ Optical density } \\
\cline { 2 - 3 } $\begin{array}{l}\text { Co-culture } \\
\text { time }\end{array}$ & Untransfected & NF- $\kappa B s i-2$ \\
\hline $12 \mathrm{~h}$ & $0.77483 \pm 0.01431$ & $0.7888 \pm 0.00026$ \\
$24 \mathrm{~h}$ & $0.7288 \pm 0.02148$ & $0.8025 \pm 0.01108^{\mathrm{a}}$ \\
$48 \mathrm{~h}$ & $0.6462 \pm 0.05151$ & $0.8397 \pm 0.02298^{\mathrm{b}}$ \\
$72 \mathrm{~h}$ & $0.6168 \pm 0.02492$ & $0.8514 \pm 0.02231^{\mathrm{b}}$ \\
$96 \mathrm{~h}$ & $0.5243 \pm 0.036065$ & $0.8636 \pm 0.02731^{\mathrm{b}}$ \\
$120 \mathrm{~h}$ & $0.4517 \pm 0.01589$ & $0.9035 \pm 0.00714^{\mathrm{b}}$ \\
\hline
\end{tabular}

${ }^{\mathrm{a}} \mathrm{P}<0.05$ vs. untransfected; ${ }^{\mathrm{b}} \mathrm{P}<0.001$ vs. untransfected. $\mathrm{n}=3 . \mathrm{NF}-\kappa \mathrm{B}$, nuclear factor- $\mathrm{\kappa B}$; si, small interfering RNA.

Table VIII. Relative Annexin A2 mRNA expression levels in human umbilical vein endothelial cells .

\section{Relative Annexin A2 mRNA}

Co-culture

time Untransfected NF- $\kappa$ Bsi-2

\begin{tabular}{rll}
\hline $12 \mathrm{~h}$ & $0.4887 \pm 0.01553$ & $0.5107 \pm 0.01723$ \\
$24 \mathrm{~h}$ & $0.4405 \pm 0.01937$ & $0.5477 \pm 0.00833^{\mathrm{a}}$ \\
$48 \mathrm{~h}$ & $0.4201 \pm 0.1339$ & $0.5503 \pm 0.01553^{\mathrm{a}}$ \\
$72 \mathrm{~h}$ & $0.3853 \pm 0.01079$ & $0.5724 \pm 0.01716^{\mathrm{b}}$ \\
$96 \mathrm{~h}$ & $0.3774 \pm 0.01495$ & $0.6202 \pm 0.02061^{\mathrm{b}}$ \\
$120 \mathrm{~h}$ & $0.2953 \pm 0.01151$ & $0.6645 \pm 0.00930^{\mathrm{b}}$
\end{tabular}

${ }^{\mathrm{a}} \mathrm{P}<0.05$ vs. untransfected; ${ }^{\mathrm{b}} \mathrm{P}<0.01$ vs. untransfected. Values are presented as the mean \pm standard deviation. $n=3$. NF- $\kappa B$, nuclear factor- $\kappa \mathrm{B}$; si, small interfering RNA.

pathogenesis remains unclear $(29,30)$. Therefore, pregnancy termination is often considered the only feasible strategy because more efficient treatments have yet to be developed. However, terminating the pregnancy is not always an acceptable solution. Due to the high mortality and disability rates in severe preeclampsia cases, early screening, prevention and diagnosis have more important roles than active treatment.

The findings of the current study indicated that serum EDLF levels were significantly higher in patients with severe preeclampsia patients compared with normal pregnant women, which indicated a potential association between EDLF and preeclampsia development. Subsequently, a Transwell system was used to co-culture hypoxic trophocytes and HUVECs for $12,24,48,72,96$ or 120 h to detect changes in EDLF protein levels. The results demonstrated that EDLF increased with increasing duration of co-culture with hypoxic cells, accompanied by a decrease in free NO. In addition, HUVEC proliferation and cellular monolayer barrier function, as well as NO production by HUVECs, changed markedly during co-culture with hypoxic trophocytes, indicating the potential for cytokine-mediated signaling between trophocytes and 
endothelial cells and corresponding effects on endothelial cell biofunctions. Using RNAi technology, NF- $\mathrm{B}$ p65 gene expression was silenced in hypoxic trophocytes, which downregulated the expression of EDLF. This led to upregulation of Annexin A2, an important EDLF target protein (38), and a decrease in HUVEC damage. Therefore, it is inferred that EDLF is a toxic factor originating from the placenta in patients with severe preeclampsia. NF- $\mathrm{KB}$ p65 may regulate EDLF expression in hypoxic trophocytes, thus influencing Annexin A2 expression and subsequent NO production. These events cause endothelial cell damage and the development of preeclampsia.

In patients with severe preeclampsia, hypoxic trophocytes produce high levels of EDLF, which is regulated by NF- $\mathrm{kB}$ p65, to elicit cytokine secretion by endothelial cells, which affects vasomotion and cell proliferation (53). Various endothelial cell functions are realized through the balance of $\mathrm{NO}$ and endothelin (ET) (20). A decrease in NO production and release may evoke an imbalance in vascular factors, with subsequent arteriole spasms and increased peripheral resistance, particularly in the kidneys, uterus and placenta, which promotes the development of hypertension and preeclampsia (31). A previous study reported that EDLF levels are significantly higher in newborn umbilical cord blood than in the peripheral blood of pregnant women (32). In addition, the previous study reported that EDLF induces the expression and release of ET-1 to initiate vasoconstriction; this upregulated the sensitivity of the vasculature to endogenous vasopressin and downregulated the relaxant effects of $\mathrm{NO}$, prostacyclin and acetylcholine, which may result in disordered vasodilatation and vasoconstriction during the development of preeclampsia (32). As a physiological stress, pregnancy creates tension in sympathetic nerves, which promotes the development of preeclampsia through exciting sympathetic nerves and eliciting a series of physiological responses, such as vasoconstriction and water and sodium retention. A previous study reported that EDLF evokes a group of sympathetic nerve excitation reactions via the release of peripheral angiotensin II (Ang II), noradrenaline and hypophysin (33), which was consistent with our previous results, namely, that Ang II has an important role in the development of preeclampsia (34). An intraperitoneal injection of EDLF increased the blood pressure of normal female rats as a consequence of upregulated ET levels in the serum and heart tissue (35). This result indicated that changes in the ET system may be one of the mechanisms by which EDLF causes hypertension and target organ damage (35). In another study, a NOS inhibitor effectively enhanced $\alpha$-adrenergic vasoconstriction, and EDLF enhanced the NOS inhibition, which indicated that EDLF increases the sensitivity to endogenous $\alpha$-adrenaline as the major mechanism of EDLF-induced vasoconstriction (36,37).

$\mathrm{NF}-\kappa \mathrm{B}$ is an essential regulator of endothelial NOS (eNOS) (38), a rate-limiting enzyme in NO synthesis that is intricately involved in physiological activities in the cardiovascular system. NO is a molecular, chemical signaling moiety that is essential for life; it has a simple structure and an extremely unstable nature, and it is produced and secreted by vascular endothelial cells and acts in a paracrine manner. Thus, NO acts on adjacent smooth muscle cells. These actions consequently increase the intracellular levels of cyclic guanosine monophosphate and cause the efflux of calcium, or promote the conversion of free calcium to bound calcium, resulting in smooth muscle relaxation and hemangiectasis (39). This is important for maintaining angiostasis and stable blood pressure. Low NO levels can cause hypertension and ischemia, resulting in damage and functional disorders in endothelial cells. Blocking NO synthesis with a NOS inhibitor in pregnant rats caused eclampsia-like symptoms (40), including hypertension, proteinuria, intrauterine growth retardation and even a high incidence of stillbirths and malformations. Thus, certain researchers recommended NO levels as a predictive index of vascular endothelial cell damage and preeclampsia (41). NO leads to hemangiectasis, inhibits the adhesion and aggregation of platelets, and blocks platelet mitosis and vascular smooth muscle cell proliferation (42). Decreased NO concentration and/or activity is considered to be a marker of endothelial damage and/or activation (43). The activity of eNOS was reported to be decreased in preeclampsia cases (44). In another animal experiment, preeclampsia-like clinical manifestations were observed in pregnant mice in which NOS activity was inhibited using drugs (45). Pregnant eNOS-knockout mice exhibited decreased blood flow in the uterus, shortened spiral artery extension and insufficient placental oxygen supply (46). The theory of imbalanced prostacyclin and thromboxane does not account for vascular disorders in pregnant women. In a recent study, a series of vascular endothelial cell-produced factors, including NO and ET, were demonstrated to have the most important roles in regulating vascular functions in pregnancy (47). Multiple studies have indicated that NO is an important factor that regulates hemodynamics to adapt to pregnancy, ensuring sufficient placental blood supply and fetal nutrition, and oxygen supply $(39,48)$. Furthermore, disorders of vascular endothelial functions, changes in ET-1 and $\mathrm{NO}$, and an imbalance in vasoconstrictors and vasodilators are key factors underlying the pathophysiological changes in preeclampsia $(31,49)$. Various endothelial cell functions are realized through the balanced secretion of NO and ET. A previous study (50) reported that endogenous ouabain, an EDLF, can inhibit the reverse flow of sodium and calcium in cells, which decreases the outflow of $\mathrm{Ca}^{2+}$ and increases its inflow. Consequently, ouabain increases the amount of $\mathrm{Ca}^{2+}$ available to smooth muscle cells and myocardial cells, thus elevating blood pressure and aggravating diseases. In pregnant women, high ouabain concentration can cause vasoconstriction and retention of water and sodium by increasing the excitation of sympathetic nerves; these humoral regulatory mechanisms, in combination with a series of signal transduction pathways, regulate the levels of vasodilators and vasoconstrictors in vivo. This phenomenon leads to an imbalance among vascular factors and the formation of a nervous-humoral regulatory network with ET, NO and rennin-angiotensin-aldosterone, which are involved in the development of preeclampsia $(51,52)$.

Annexin A2 is an important functional target protein of EDLF (21). Endothelial cells that express Annexin A2 may serve as receptors for fibrinolysin, zymogens and tissue-type plasminogen activator (t-PA). Annexin A2, as a t-PA cofactor, has an important role in the generation of plasmin, the release of endothelial adhesion molecules, and the migration and adhesion of endothelial cells $(53,54)$.

In preeclampsia cases, vascular endothelial cells, vascular smooth muscle cells and white blood cells are activated via the NF- $\kappa \mathrm{B}$ pathway. Activated NF- $\kappa \mathrm{B}$ can upregulate the 
expression of various genes, including those for epidermal growth factor and platelet-derived growth factor. These events are often followed by vascular smooth muscle cell proliferation, intramembrane signaling for vascular remodeling, and subsequent increases in the level of collagenous fibers, the thickness of vessel walls and the mean pressure in arterioles. These changes subsequently elicit the clinical manifestations of hypertensive disorders complicating pregnancy, including hypertension, proteinuria and edema $(18,55)$.

In the current study, hypoxic trophocytes were co-cultured with HUVECs. RNAi technology was used to silence the $\mathrm{NF}-\kappa \mathrm{B}$ p65 gene in hypoxic trophocytes, which resulted in reduced EDLF levels. By contrast, the expression of Annexin A2, an EDLF target protein, was upregulated in HUVECs, and NO production increased. Furthermore, the monolayer barrier function and HUVEC proliferation were increased by $\mathrm{NF}-\kappa \mathrm{B}$ silencing in hypoxic trophocytes. These results suggested that $\mathrm{NF}-\kappa \mathrm{B}$ p65 may affect Annexin A2 expression in HUVECs by regulating EDLF production in hypoxic trophocytes, which impairs vascular endothelial cell function and NO secretion.

The results of the current study demonstrated the effects of EDLF only in terms of vascular endothelial cell damage. However, EDLF also plays a maintenance role in normal pregnancy. The levels of EDLF that lead to positive and negative effects remain to be determined via analysis of a large number of samples. The results of such an analysis may lead to the development of a sensitive and specific marker for convenient, rapid and reproducible early diagnosis and monitoring, and for assessing therapeutic effects. EDLF causes vascular endothelial cell damage through multiple pathways; this study focused on only the $\mathrm{NF}-\kappa \mathrm{B}$ p65 pathway. Further comprehensive studies of multiple pathways may contribute more valuable information regarding preeclampsia pathogenesis.

In conclusion, high levels of EDLF may have an important role in the multifactorial pathogenesis of preeclampsia, and $\mathrm{NF}-\kappa \mathrm{B}$ p65 is a potential key factor in the regulation of EDLF concentration in preeclampsia. The results of this study may provide novel strategies for intervening in the development of preeclampsia in clinical practice.

\section{References}

1. Liu Q and Yang J: Expression and significance of miR155 and vascular endothelial growth factor in placenta of rats with preeclampsia. Int J Clin Exp Med 8: 15731-15737, 2015.

2. ACOGCommittee on Obstetric Practice: ACOG practice bulletin. Diagnosis and management of preeclampsia and eclampsia. Number 33, January 2002. American College of Obstetricians and Gynecologists. Int J Gynaecol Obstet 77: 67-75, 2002.

3. Solomon CG and Seely EW: Preeclampsia - searching for the cause. N Engl J Med 350: 641-642, 2004.

4. Merviel P, Carbillon L, Challier JC, Rabreau M, Beaufils M and Uzan S: Pathophysiology of preeclampsia: Links with implantation disorders. Eur J Obstet Gynecol Reprod Biol 115: 134-147, 2004.

5. Wang YY, Zhou R, Zhou B, Wang T, Zhang L and Luo D: Overexpression of heparanase is associated with preeclampsia by inhibiting invasion of trophocytes. Int J Clin Exp Med 8: 18107-18114, 2015.

6. Stella P, Manunta P, Mallamaci F, Melandri M, Spotti D, Tripepi G, Hamlyn JM, Malatino LS, Bianchi G and Zoccali C: Endogenous ouabain and cardiomyopathy in dialysis patients. J Intern Med 263: 274-280, 2008.

7. Takahashi H, Yoshika M, Komiyama Y and Nishimura M: The central mechanism underlying hypertension: A review of the roles of sodium ions, epithelial sodium channels, the renin-angiotensin-aldosterone system, oxidative stress and endogenous digitalis in the brain. Hypertens Res 34: 1147-1160, 2011
8. Lv ZR, Sha HJ and Hamillon BP: The experimental investigation on the biosynthetic pathway of endogenous ouabain. Chin J Pathophy 14: 913, 1998 (In Chinese).

9. Dechend R, Viedt C, Müller DN, Ugele B, Brandes RP, Wallukat G, Park JK, Janke J, Barta P, Theuer J, et al: AT1 receptor agonistic antibodies from preeclamptic patients stimulate NADPH oxidase. Circulation 107: 1632-1639, 2003.

10. Vento-Tormo R, Rodríguez-Ubreva J, Lisio LD, Islam AB, Urquiza JM, Hernando H, López-Bigas N, Shannon-Lowe C, Martínez N, Montes-Moreno S, et al: NF- $\kappa \mathrm{B}$ directly mediates epigenetic deregulation of common microRNAs in Epstein-Barr virus-mediated transformation of B-cells and in lymphomas. Nucleic Acids Res 42: 11025-11039, 2014.

11. Castri P, Lee YJ, Ponzio T, Maric D, Spatz M, Bembry J and Hallenbeck J: Poly(ADP-ribose) polymerase-1 and its cleavage products differentially modulate cellular protection through NF-kappaB-dependent signaling. Biochim Biophys Acta 1843: 640-651, 2014.

12. Hu WT, Huang LL, Li MQ, Jin LP, Li DJ and Zhu XY: Decidual stromal cell-derived IL-33 contributes to Th2 bias and inhibits decidual NK cell cytotoxicity through NF- $\kappa \mathrm{B}$ signaling in human early pregnancy. J Reprod Immunol 109: 52-65, 2015.

13. Yu LJ, Wang B, Parobchak N, Roche N and Rosen T: STAT3 cooperates with the non-canonical NF- $\mathrm{BB}$ signaling to regulate pro-labor genes in the human placenta. Placenta 36: 581-586, 2015.

14. Yu Y, Wang L, Tang W, Zhang D and Shang T: RNA interference-mediated knockdown of Notch-1 inhibits migration and invasion, downregulates matrix metalloproteinases and suppresses NF- $\mathrm{KB}$ signaling pathway in trophoblast cells. Acta Histochem 116: 911-919, 2014.

15. Simsek Y, Gul M, Celik O, Aydin NE, Arda Düz S, Celik E, Ozerol E, Özerol IH and Tanbek K: Nuclear transcription factor-kappa beta-dependent ultrastructural alterations within the placenta and systemic inflammatory activation in pregnant patients with hemolysis, elevated liver functions and low thrombocyte count (HELLP) syndrome: A case-control study. Hypertens Pregnancy 32: 281-291, 2013.

16. Huang LL, Su S, Awale R, Zhang XY, Zhong LL and Tang H: Expression of anti-inflammatory mediator lipoxin A4 and inflammation responsive transcriptive factors NF-kappa B in patients with preeclampsia. Clin Exp Obstet Gynecol 41: 561-566, 2014.

17. Xue P, Zheng M, Gong P, Lin C, Zhou J, Li Y, Shen L, Diao Z, Yan G, Sun H, et al: Single administration of ultra-low-dose lipopolysaccharide in rat early pregnancy induces TLR4 activation in the placenta contributing to preeclampsia. PLoS One 10: $\mathrm{e} 0124001,2015$.

18. Vaughan JE and Walsh SW: Activation of NF- $\kappa$ B in placentas of women with preeclampsia. Hypertens Pregnancy 31: 243-251, 2012.

19. Craici IM, Wagner SJ, Weissgerber TL, Grande JP and Garovic VD: Advances in the pathophysiology of pre-eclampsia and related podocyte injury. Kidney Int 86: 275-285, 2014.

20. Dai R, Phillips RA, Karpuzoglu E, Khan D and Ahmed SA: Estrogen regulates transcription factors STAT-1 and NF-kappaB to promote inducible nitric oxide synthase and inflammatory responses. J Immunol 183: 6998-7005, 2009.

21. Qiu J: Proteomics analysis of effect of endogeneous digitalis-like substance on human endothelial cells. PhD Degree Thesis of Shandong University, 2007.

22. Wu YJ, Zheng LL and Xin H: Changes and clinical significance of Annexin A2 and its antibody in patients with preeclampsia. Chin Gen Pract 15: 1575-1578, 2012.

23. Xie X and Gou WL: Obstetrics and Gynecology. People's Medical Publishing House, Beijing, pp264-267, 2013.

24. Dasgupta A, Kang E and Datta P: The new enzyme-linked immunosorbent digoxin assay on the ADVIA Integrated Modular System is virtually free from oleander interference. Ther Drug Monit 28: 282-285, 2006.

25. Amitava D and Meredith AR: Ginseng and digoxin assays. Discussion. Am J Clin Pathol 124: 229-236, 2005.

26. Reyes MA, Actor JK, Risin SA and Dasgupta A: Effect of Chinese medicines Chan Su and Lu-Shen-Wan on serum digoxin measurement by Digoxin III, a new digoxin immunoassay. Ther Drug Monit 30: 95-99, 2008.

27. Benaitreau D, Dos Santos E, Leneveu MC, De Mazancourt P, Pecquery R and Dieudonné MN: Adiponectin promotes syncytialisation of BeWo cell line and primary trophoblast cells. Reprod Biol Endocrinol 8: 128, 2010.

28. Egger D and Bienz K: Protein (western) blotting. Mol Biotechnol 1: 289-305, 1994. 
29. Bilano VL, Ota E, Ganchimeg T, Mori R and Souza JP: Risk factors of pre-eclampsia/eclampsia and its adverse outcomes in low- and middle-income countries: A WHO secondary analysis. PLoS One 9: e91198, 2014.

30. Hund M, Allegranza D, Schoedl M, Dilba P, Verhagen-Kamerbeek W and Stepan H: Multicenter prospective clinical study to evaluate the prediction of short-term outcome in pregnant women with suspected preeclampsia (PROGNOSIS): Study protocol. BMC Pregnancy Childbirth 14: 324, 2014.

31. Ishkaraeva-Yakovleva VV, Fedorova OV, Solodovnikova NG, Frolova EV, Bzhelyansky AM, Emelyanov IV, Adair CD, Zazerskaya IE and Bagrov AY: DigiFab interacts with endogenous cardiotonic steroids and reverses preeclampsia-induced $\mathrm{Na}$ /K-ATPase inhibition. Reprod Sci 19: 1260-1267, 2012.

32. Blaustein MP and Hamlyn JM: Signaling mechanisms that link salt retention to hypertension: Endogenous ouabain, the $\mathrm{Na}(+)$ pump, the $\mathrm{Na}(+) / \mathrm{Ca}(2+)$ exchanger and TRPC proteins. Biochim Biophys Acta 1802: 1219-1229, 2010.

33. Fedorova OV, Agalakova NI, Talan MI, Lakatta EG and Bagrov AY: Brain ouabain stimulates peripheral marinobufagenin via angiotensin II signalling in NaCl-loaded Dahl-S rats. J Hypertens 23: 1515-1523, 2005.

34. Ding YL, Yu L and Hu Y: Expression of angiotensin II type 1 receptor and angiotensinogen in preeclamptic placenta. Chin J Perina Med 17: 269-271, 2004.

35. Takahashi H: Upregulation of the Renin-Angiotensin-aldosteroneouabain system in the brain is the core mechanism in the genesis of all types of hypertension. Int J Hypertens 2012: 242786, 2012.

36. Xavier FE, Salaices M, Márquez-Rodas I, Alonso MJ, Rossoni LV, Vassallo DV and Balfagón G: Neurogenic nitric oxide release increases in mesenteric arteries from ouabain hypertensive rats. J Hypertens 22: 949-957, 2004.

37. Xavier FE, Rossoni LV, Alonso MJ, Balfagón G, Vassallo DV and Salaices M: Ouabain-induced hypertension alters the participation of endothelial factors in alpha-adrenergic responses differently in rat resistance and conductance mesenteric arteries. Br J Pharmacol 143: 215-225, 2004.

38. Ramírez-Vélez R, Bustamante J, Czerniczyniec A, Aguilar de Plata AC and Lores-Arnaiz S: Effect of exercise training on eNOS expression, NO production and oxygen metabolism in human placenta. PLoS One 8: e80225, 2013.

39. Odibo AO, Zhong Y, Longtine M, Tuuli M, Odibo L, Cahill AG, Macones GA and Nelson DM: First-trimester serum analytes, biophysical tests and the association with pathological morphometry in the placenta of pregnancies with preeclampsia and fetal growth restriction. Placenta 32: 333-338, 2011.

40. Fernández Celadilla L, Carbajo Rueda M and Muñoz Rodríguez M: Prolonged inhibition of nitric oxide synthesis in pregnant rats: Effects on blood pressure, fetal growth and litter size. Arch Gynecol Obstet 271: 243-248, 2005.

41. Var A, Yildirim Y, Onur E, Kuscu NK, Uyanik BS, Goktalay K and Guvenc Y: Endothelial dysfunction in preeclampsia. Increased homocysteine and decreased nitric oxide levels. Gynecol Obstet Invest 56: 221-224, 2003.

42. Song H, Karashima E, Hamlyn JM and Blaustein MP: Ouabain-digoxin antagonism in rat arteries and neurones. J Physiol 592: 941-969, 2014.
43. Gilbert JS, Ryan MJ, LaMarca BB, Sedeek M, Murphy SR and Granger JP: Pathophysiology of hypertension during preeclampsia: Linking placental ischemia with endothelial dysfunction. Am J Physiol Heart Circ Physiol 294: H541-H550, 2008.

44. López-Jaramillo P, Arenas WD, García RG, Rincon MY and López M: The role of the L-arginine-nitric oxide pathway in preeclampsia. Ther Adv Cardiovasc Dis 2: 261-275, 2008.

45. Pisaneschi S, Strigini FA, Sanchez AM, Begliuomini S, Casarosa E, Ripoli A, Ghirri P, Boldrini A, Fink B, Genazzani AR, et al: Compensatory feto-placental upregulation of the nitric oxide system during fetal growth restriction. PLoS One 7: e45294, 2012.

46. Sathishkumar K, Elkins R, Chinnathambi V, Gao H, Hankins GD and Yallampalli C: Prenatal testosterone-induced fetal growth restriction is associated with downregulation of rat placental amino acid transport. Reprod Biol Endocrinol 9: 110, 2011.

47. Johal T, Lees CC, Everett TR and Wilkinson IB: The nitric oxide pathway and possible therapeutic options in pre-eclampsia. Br J Clin Pharmacol 78: 244-257, 2014.

48. Mangialardi G, Monopoli A, Ongini E, Spinetti G, Fortunato O, Emanueli $\mathrm{C}$ and Madeddu P: Nitric oxide-donating statin improves multiple functions of circulating angiogenic cells. Br J Pharmacol 164: 570-583, 2011.

49. Maron BA, Oldham WM, Chan SY, Vargas SO, Arons E, Zhang YY, Loscalzo J and Leopold JA: Upregulation of steroidogenic acute regulatory protein by hypoxia stimulates aldosterone synthesis in pulmonary artery endothelial cells to promote pulmonary vascular fibrosis. Circulation 130: 168-179, 2014.

50. Jacobs BE, Liu Y, Pulina MV, Golovina VA and Hamlyn JM: Normal pregnancy: Mechanisms underlying the paradox of a ouabain-resistant state with elevated endogenous ouabain, suppressed arterial sodium calcium exchange, and low blood pressure. Am J Physiol Heart Circ Physiol 302: H1317-H1329, 2012.

51. Saunders R and Scheiner-Bobis G: Ouabain stimulates endothelin release and expression in human endothelial cells without inhibiting the sodium pump. Eur J Biochem 271: 1054-1062, 2004.

52. Kaur G, Kapoor N, Mohan P, Sri Nageswari K, Singh MJ and Prasad R: Alteration in ouabain-sensitive sodium potassium pump of erythrocytes during pregnancy induced hypertension: A kinetic study. J Biochem Mol Biol Biophys 6: 163-166, 2002.

53. Harvey KA, Xu Z, Pavlina TM, Zaloga GP and Siddiqui RA: Modulation of endothelial cell integrity and inflammatory activation by commercial lipid emulsions. Lipids Health Dis 14: 9 , 2015.

54. Bharadwaj A, Bydoun M, Holloway R and Waisman D: Annexin A2 heterotetramer: Structure and function. Int J Mol Sci 14: 6259-6305, 2013.

55. Wu YH, Chiu DT, Lin HR, Tang HY, Cheng ML and Ho HY: Glucose-6-phosphate dehydrogenase enhances antiviral response through downregulation of NADPH sensor HSCARG and upregulation of NF-кB signaling. Viruses 7: 6689-6706, 2015. 